\title{
Dynamics of relationship between the presence of Coxiella burnetii DNA, antibodies, and intrinsic variables in cow milk and bulk tank milk from Danish dairy cattle
}

\author{
Ø. Angen, ${ }^{\star 1}$ M. Ståhl, ${ }^{\star}$ J. S. Agerholm,† A.-B. Christoffersen, ${ }^{*}$ and J. F. Agger† \\ *National Veterinary Institute, Technical University of Denmark, Bülowsvej 27, DK-1790 Copenhagen V, Denmark \\ †Department of Large Animal Sciences, Faculty of Life Sciences, University of Copenhagen, Bülowsvej 17, DK-1870 Frederiksberg C, Denmark
}

\begin{abstract}
Milk samples of 12 Danish dairy herds were collected 3 times during an 11-mo period and tested for Coxiella burnetii DNA by real-time PCR, detecting the IS1111 element, and for the presence of antibodies against the bacterium by ELISA. On average, $25 \%$ of 1,514 samples were seropositive and $32 \%$ were positive for $C$. burnetii DNA. Among the 485 DNA-positive samples, quantification cycle values ranging from 15.8 to 37.8 were found. Test sensitivity did not increase after DNA extraction from the cream fraction compared with full milk. The relationship between antibody levels and bacterial shedding was investigated among 166 cows from 9 herds. The prevalence levels of $C$. burnetii DNA and antibodies in the herds were found to be rather stable for 6 of the herds. The test results were highly influenced by results obtained 3 to 7 mo earlier. A significant association between the antibody titer and the DNA shedding level at the same and the preceding visit was found. In addition, a significant association between the antibody titer and the antibody titers 3 to $11 \mathrm{mo}$ earlier was found. A multivariable analysis identified a significant increase in C. burnetii DNA shedding with increasing parity and increasing protein concentration in milk. The antibody levels in bulk tank milk and prevalence levels of $C$. burnetii DNA and antibodies in individual cow milk samples were correlated. A significant correlation was also found between the quantification cycle values of the cow samples (weighted according to milk yield) and the $C$. burnetii concentration in bulk tank milk.
\end{abstract}

Key words: Coxiella burnetii, quantitative polymerase chain reaction, milk serology, milk shedding

\section{INTRODUCTION}

Q-fever is a zoonosis caused by the intracellular bacterium Coxiella burnetii. This bacterium occurs world-

Received January 21, 2011.

Accepted September 2, 2011.

${ }^{1}$ Corresponding author: oang@vet.dtu.dk wide and infects many animal species. Cattle, sheep, and goats are considered the main reservoirs for human infections (Maurin and Raoult, 1999). In humans, the acute infection may induce a flu-like and usually selflimiting disease. Chronic infections may be associated with endocarditis and hepatitis. Reproductive disorders are observed in sheep and goats, whereas the infection in cattle mostly remains clinically unrecognized (Rodolakis et al., 2007; Rodolakis, 2009).

Antibodies in milk against $C$. burnetii have been detected in cattle in many countries with herd prevalences between 18 and 94\% (Guatteo et al., 2011). In Denmark, $57 \%$ of 742 non-randomly selected cattle herds were found to be antibody positive in bulk tank milk (BTM) samples (Bødker and Christoffersen, 2008), whereas in a more recent study, 59\% of 100 randomly selected herds were found to be antibody positive (Agger et al., 2010).

Real-time PCR is a suitable technique to estimate the amount of DNA in clinical samples including quantification of $C$. burnetii. Detection of bacterial shedders is important to investigate the spread of $C$. burnetii among animals and from animals to humans and to assess the potential zoonotic risk. Coxiella burnetii is shed mainly in birth products such as fluids and placenta, but may also be excreted in feces, urine, vaginal mucus, and milk (Rodolakis, 2009; Hansen et al., 2011). In cattle, milk has been shown to be a significant route of shedding (Guatteo et al., 2007a) and indications exist that $C$. burnetii may induce inflammation of the mammary gland in cattle (Barlow et al., 2008). A direct relation between serology and PCR results has not been observed, as seronegative animals may shed C. burnetii and seropositive animals might not excrete the organism continuously (Guatteo et al., 2007a; Rodolakis et al., 2007).

Knowledge is still limited on the relationship between the secretion of bacteria and antibodies in milk and intrinsic cow variables over time. In the present study, 12 Danish dairy herds were followed by repeated sampling of cow milk and BTM during 12 consecutive months and tested by ELISA and quantitative PCR (qPCR). 
The relationship between intrinsic cow variables, DNA shedding pattern, and serological response was investigated by multivariate analysis.

\section{MATERIALS AND METHODS}

\section{Sampling and Antibody Detection}

Twelve herds were recruited among 100 randomly selected Danish dairy herds examined for BMT antibodies against $C$. burnetii once in the spring 2008 (Agger et al., 2010). The herds consisted of 10 randomly selected herds among the test-positive herds; in addition, 1 BTM test-intermediate herd and 1 BTM test-negative herd (although with ELISA, test-positive cow samples) were selected (Figure 1). The study design of the individual herds was cross-sectional with follow up.

The antibody level was determined by the CHEKIT Q-fever Antibody ELISA Test Kit (IDEXX Laboratories Inc., Liebefeld-Bern, Switzerland). The kit determines the antibody level as a sample/positive control $(\mathbf{S} / \mathbf{P})$ value, being the ratio between the optical density (OD) of the sample and the OD of a positive control, where both the numerator and denominator are corrected for the OD of the negative control. According to the producer, $\mathrm{S} / \mathrm{P}$ values $\geq 40$ should be regarded as positive, whereas the values between 30 and 40 are doubtful. In the analysis, we chose to regard $\mathrm{S} / \mathrm{P}$ values $<40$ as negative.

Individual cow milk samples were collected at 3 sampling dates from all cows with an interval of 3 to 7 mo. On average, 46 of these milk samples were selected per herd from each sampling event (with an exception of herd number 108, third sampling; see Table 1) and analyzed for the presence of $C$. burnetii DNA by a semiquantitative $\mathrm{PCR}$ on the cream fraction and for the presence of antibodies by ELISA. A total of 1,514 milk samples from 841 cows were examined. The sampling proportion among the herds varied from $11 \%$ in a herd with more than 400 cows to $100 \%$ in a small herd with 44 cows (Table 1). The sample sizes of 46 were sufficient to estimate the prevalences at the 3 sampling dates with an allowable error of \pm 0.12 in all herds.

Bulk tank milk samples were collected from the 12 herds once every month, in total 13 times, starting in July 2008. In total, 151 BTM samples (5 samples were lost) were analyzed for the presence of $C$. burnetii antibodies by ELISA and for the concentration of $C$. burnetii DNA in full milk by qPCR.

\section{Sample Preparation for PCR}

Milk samples (approximately $5 \mathrm{~mL}$ ) were stored at $-20^{\circ} \mathrm{C}$ until analysis. Approximately $200 \mu \mathrm{L}$ of the cream layer from the cow milk samples was collected in a $2.0-\mathrm{mL}$ microcentrifuge tube and stored at $-20^{\circ} \mathrm{C}$. The cream samples were heated to $37^{\circ} \mathrm{C}$ for $15 \mathrm{~min}$ on a mixing table KS 250 basic (IKA Labortechnik, Staufen, Germany), and then washed twice with $1 \mathrm{~mL}$ of PBS by vortexing on a Vibrofix VF 1 electronic vortexer (Janke \& Kunkel, IKA Labortechnik) at 2,500 $\mathrm{rpm}$ and centrifuged at $6,000 \times g$ for $10 \mathrm{~min}$. The pellets were resuspended in $600 \mu \mathrm{L}$ of PBS and stored at $-20^{\circ} \mathrm{C}$. The samples were heated to $37^{\circ} \mathrm{C}$, mixed, and centrifuged at $6,000 \times g$ for 10 min before extraction. The pellets were resuspended in $180 \mu \mathrm{L}$ of lysis buffer ATL (Qiagen GmbH, Hilden, Germany) with $20 \mu \mathrm{L}$ of proteinase K (>600 milli-Anson units $(\mathrm{AU}) / \mathrm{mL}$; Qiagen $\mathrm{GmbH}$ ). After vortexing, samples were incubated at $56^{\circ} \mathrm{C}$ overnight in a digital block heater (Buch \& Holm, Herlev, Denmark). The DNA was extracted from the lysates in a QIAsymphony robot (Qiagen $\mathrm{GmbH}$ ) with a QIAsymphony DNA Mini Kit (Qiagen $\mathrm{GmbH}$ ) on program Tissue LC 200 and subsequently eluted in $50 \mu \mathrm{L}$ of ATE buffer (Qiagen $\mathrm{GmbH}$ ). A suspension of Escherichia coli was used as negative extraction control in all DNA extractions.

The DNA extraction from cream was compared with extraction from full milk. Fifty-five milk samples were divided after heating to $37^{\circ} \mathrm{C}$ for $1 \mathrm{~h}$ and vortexed for $1 \mathrm{~min}$. The DNA was extracted directly from $200 \mu \mathrm{L}$ of milk in the QIAsymphony robot after proteinase $\mathrm{K}$ treatment, as described above. The rest of the milk was kept at $4^{\circ} \mathrm{C}$ overnight; thereafter, the cream was collected and treated as described above. Deoxyribonucleic acid was extracted in the QIAsymphony robot from 200 $\mu \mathrm{L}$ of the BTM samples (full milk) after proteinase K treatment, as described above.

\section{qPCR}

Quantitative PCR, detecting the insertion sequence (IS)1111 element, was performed in duplicate with $5 \mu \mathrm{L}$ of sample in a total reaction volume of $25 \mu \mathrm{L}$. The reaction mixture was modified from Panning et al. (2008) by substituting the internal control probe with $0.2 \mu M$ Coxlam (Applied Biosystems, Warrington, $\mathrm{UK}$ ) and adding $5 \mu \mathrm{L}$ of the PCR-generated internal control (IC) diluted $10^{-8}$ (the IC DNA was adjusted to a level where it did not interfere with the magnitude of the C. burnetii-specific reaction.). The primers were CoxbS (gatagcccgataagcatcaac, nt position 1241-1261, GenBank accession M80806; Applied Biosystems) and CoxbAs (gcattcgtatatccggcatc, nt 1326-1307; Applied Biosystems) and the $C$. burnetii-specific probe was CoxbMGB (tcatcaaggcaccaat, nt 1272-1287; Applied Biosystems; Panning et al., 2008). The IC used as an internal amplification control of $250 \mathrm{bp}$ was made by 


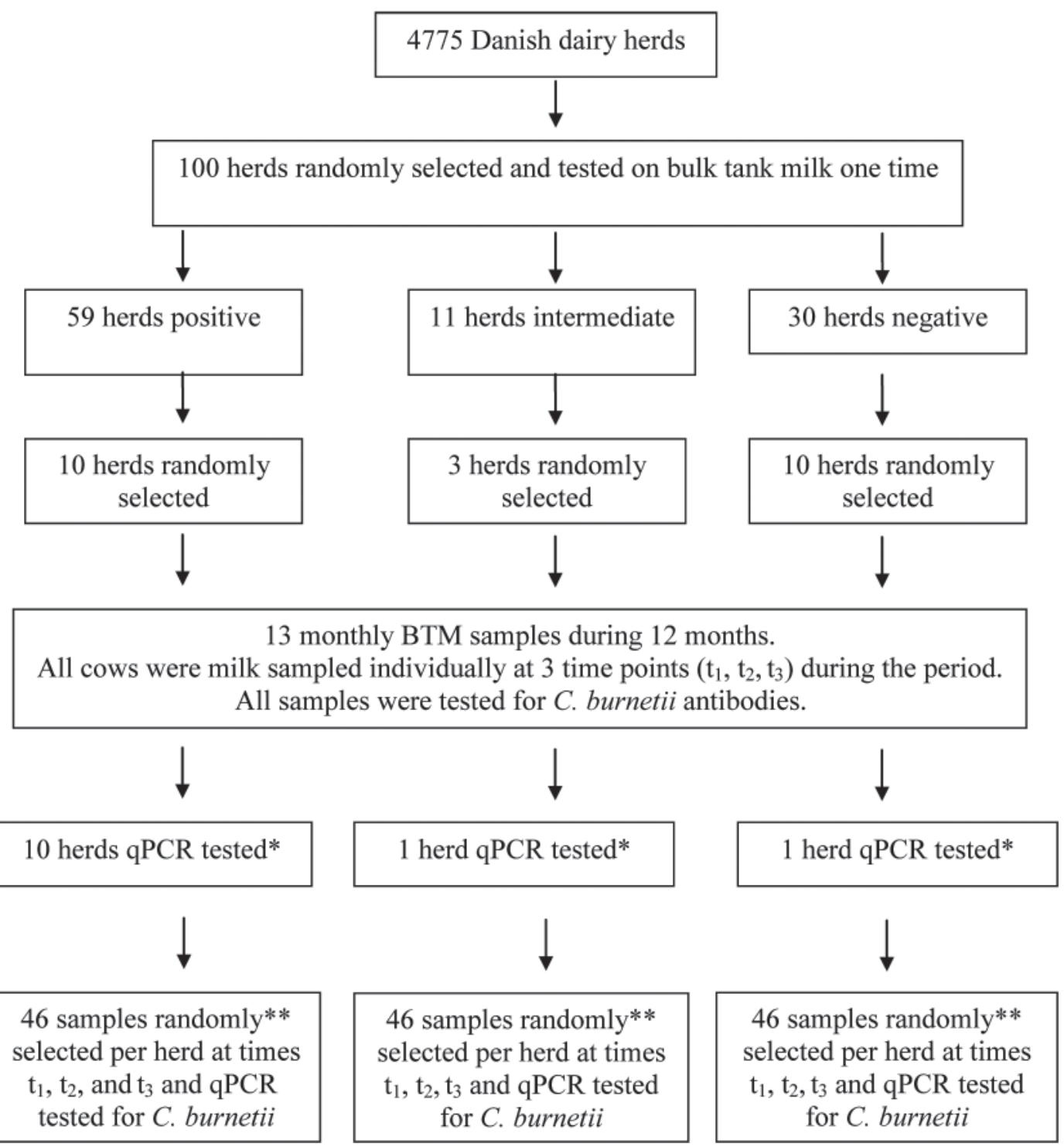

Figure 1. Study design, herd selection, and scheme for milk sampling. BTM = bulk tank milk; C. burnetii = Coxiella burnetii; $\mathrm{qPCR}=$ quantitative PCR. ${ }^{*}$ PCR testing of all monthly BTM samples. ${ }^{*}$ Samples were selected at random at time $t_{1}$. Sampling at times $t_{2}$ and $t_{3}$ were from the same cows sampled at the first screening (time $t_{1}$ ), if possible, in order to maximize the number of repeated measurements. The rest of the cows were selected at random.

amplifying lambda DNA (Invitrogen A/S, Taastrup, Denmark) with primer F CoxLam (gatagcccgataagcatcaaccgcatgaatatgaccagccaac; TAG Copenhagen A/S, Copenhagen, Denmark) and R CoxLam (gcattcgtatatccggcatcattcacgcaggggaaatatctttc; TAG Copenhagen $\mathrm{A} / \mathrm{S})$. In the qPCR reaction, IC was detected by probe Coxlam (ccacgaagccgcacgactccgc; Applied Biosystems). The CoxbMGB was labeled with 5'FAM, Coxlam was labeled with $5^{\prime} \mathrm{VIC}$, and both were labeled with $3^{\prime}$ minor groove binder non-fluorescent quencher. All tests were run on Rotor-Gene 3000 or 6000 (Corbett Research, Mortlake, NSW, Australia).
In all $\mathrm{qPCR}$, one sample of pure DNA from $C$. burnetii Nine Mile strain RSA 493 (Statens Serum Institut, Copenhagen, Denmark) was run in triplicate as positive control. The $C$. burnetii Nine Mile DNA was purified manually with QIAamp DNA Mini Kit (Qiagen $\mathrm{GmbH}$ ) according to the recommendations of the manufacturer after incubation at $56^{\circ} \mathrm{C}$ overnight with lysis buffer ATL and Proteinase $\mathrm{K}$, as described above. The concentration of the positive control DNA was equivalent to $10^{2}$ bacteria $/ \mathrm{mL}$ as analyzed by the PCR Kit TaqVet C. burnetii (LSI-Laboratoire Service International, Lissieu, France). Mastermix (modified 
Table 1. Analysis of data from all 1,514 milk samples representing 841 cows tested 1 to 3 times each

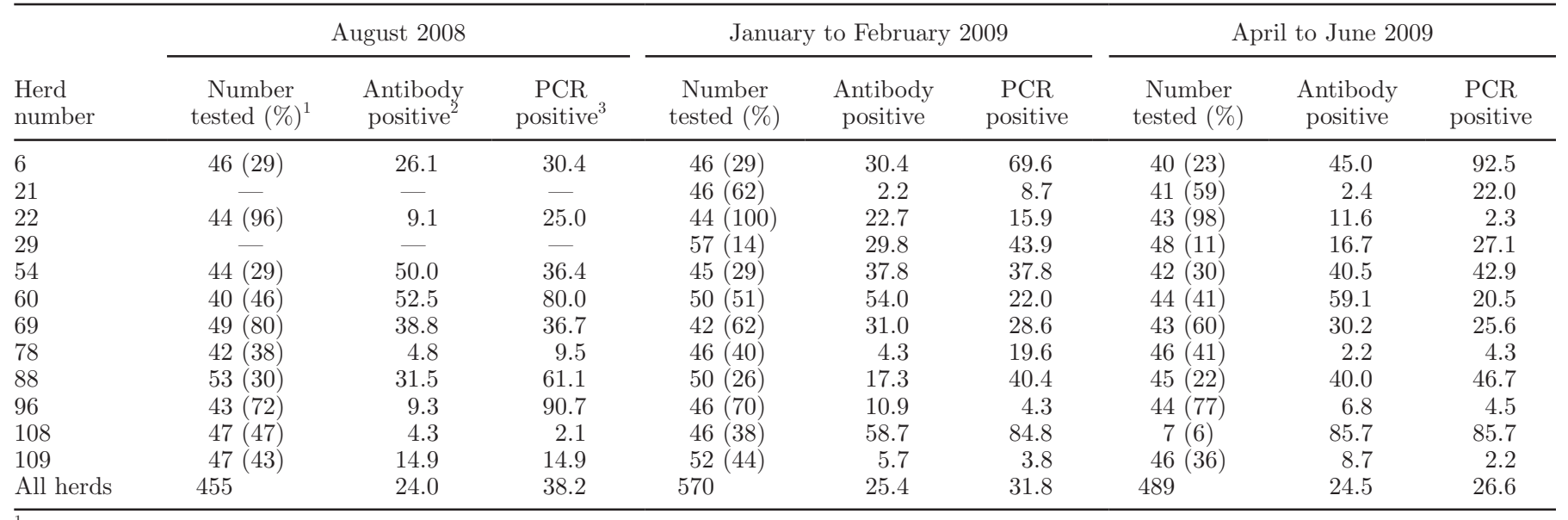

${ }^{1}$ Proportion tested.

${ }^{2}$ Percent test positive [sample/positive control $(\mathrm{S} / \mathrm{P})$ value $\left.\geq 40\right]$.

${ }^{3}$ Percent test positive [quantification cycle $(\mathrm{Cq})$ value $<38$ ].

from Panning et al., 2008; see above) was used as no template control.

For positive samples having a typical amplification curve, the results were given as quantification cycle (Cq) values. A Cq value of 38 was used as the cut-off, based on dilution experiments with the positive control.

The concentrations of $C$. burnetii in the BTM samples were determined from a standard curve made from defined amounts of $C$. burnetii cells (Nine Mile strain) kindly supplied by E. Rousset [Agence nationale de sécurité sanitaire de l'alimentation, de l'environnement et du travail (ANSES), Maisons-Alfort, France]. The dynamic range extended from $5 \times 10^{1}$ to $5 \times 10^{8}$ cells/ $\mathrm{mL}$.

\section{Statistical Methods}

The mean of the $\mathrm{Cq}$ values from the duplicate tests were used for analysis. If only 1 of the $\mathrm{Cq}$ values was below 38 , this value was used. For the regression analyses, the $\mathrm{qPCR}$ values were transformed to an ordinal scale with the purpose of including the test-negative results in the analysis: 0 (negatives, $\mathrm{Cq} \geq 38), 1$ ( $33 \leq$ $\mathrm{Cq}<38), 2(28 \leq \mathrm{Cq}<33)$, and $3(\mathrm{Cq}<28)$.

For making summary statistics, the $\mathrm{S} / \mathrm{P}$ value was used as a dichotomous variable, where $\mathrm{S} / \mathrm{P}$ values $\geq 40 \%$ were considered positive. For the regression analyses, the $\mathrm{S} / \mathrm{P}$ values were treated as a continuous variable.

To test the association between $\mathrm{S} / \mathrm{P}$ values and $\mathrm{Cq}$ values, only the cows that had been sampled at all 3 occasions were used. This included 498 samples from 166 cows. A mixed regression model was analyzed using $\mathrm{S} / \mathrm{P}$ values as dependent variable, herd as random effect, and $\mathrm{qPCR}$ results as independent variable. Models including $\mathrm{S} / \mathrm{P}$ and $\mathrm{qPCR}$ values of the preceding visits were also evaluated.

Analysis for relationship between qPCR and intrinsic cow variables was based on a mixed regression model accounting for repeated measures of production traits and the herd as random effect. The intrinsic cow variables originated from the Danish Cattle Database, which continuously is updated with information about production data from all Danish cattle herds. All analyses were performed using SAS (SAS Institute Inc., Cary, NC).

\section{RESULTS}

\section{qPCR Test Performance}

Among the 1,514 milk samples, 485 positive samples with $\mathrm{Cq}$ values ranging from 15.8 to 37.8 were found (no $\mathrm{Cq}$ values $>38$ were observed), whereas 1,029 samples were negative. Thus, the crude overall prevalence of $C$. burnetii shedders was $32 \%$. The distribution of positive values using the ordinal scale was 1 (28\%), 2 (41\%), and 3 (31\%; Supplementary Figure 1, available at http:// www.journalofdairyscience.org/). A similar distribution was found when analyzing samples from the 166 cows that had been sampled at all 3 occasions (data not shown).

The positive DNA control used in all runs had a constant $\mathrm{Cq}$ value between 27 and 28 . When a 10 -fold dilution series of the positive control was tested, the PCR efficiency was $1.09\left(\mathrm{R}^{2}=0.995\right)$ and the dynamic range was $4 \log$ units. The IC had a Cq value between 24 and 25 in all reactions, except in some of the samples with very high concentrations of $C$. burnetii $(\mathrm{Cq}$ values below 25), showing that inhibition did not have de- 
tectable influence on the analysis. Preliminary testing before the start of the project had indicated that the sensitivity of the analysis was improved when analyzing the cream layer compared with cell pellet (data not shown). However, when the diagnostic sensitivities of extraction from raw milk and cream layer were compared more rigorously (taking place after the analyses were finished), no statistical significant difference in the number of positive samples were found ( $P=0.44$, chisquared test).

\section{Detection of C. burnetii Milk Shedders and Milk Antibodies}

The number of $C$. burnetii shedders showed an overall small and significant declining trend $(P<0.001$, Cochrane-Armitage trend test) from $38.2 \%$ in August 2008, to $31.8 \%$ in January to February 2009, to $26.6 \%$ in April to June 2009 (Table 1). Marked differences in shedding levels were observed among the 12 herds, with shedding prevalences ranging from 2.1 to $92.5 \%$. The milk antibody prevalence levels were overall at the same level (24.0-25.5\%) at all 3 time points. Also, marked differences in herd prevalences were observed, ranging from 2.2 to $85.7 \%$ positive samples (Table 1).

\section{Comparison of Shedding of C. burnetii and Antibodies in Cow Milk Samples}

To investigate further the association between qPCR and ELISA results, a reduced data set was analyzed, including only the 166 cows that had been sampled at all 3 occasions (Supplementary Table 1, available at http://www.journalofdairyscience.org/). This excluded all milk samples from 3 of the herds (No. 21, 29 , and 60). The 9 herds showed marked differences in the prevalences both by qPCR and ELISA, and generally, the 2 parameters had a similar numerical level (Figure 2; e.g., low levels in herds 22, 78, and 109, and intermediate levels in herds 54,69, and 88). In herd 6 , a marked increase in the number of $\mathrm{qPCR}$ positives was observed, whereas the prevalence of ELISA positives remained constant. In herd 96, the number of $C$. burnetii shedders decreased markedly from the first to the second sampling, whereas a constant low level of ELISA positives was found at all 3 samplings. However, only low levels of $C$. burnetii DNA $(\mathrm{Cq}>33)$ were found in this herd in August 2008. In herd 108, a marked increase occurred in both qPCR and ELISA levels from the first to the second sampling.

In the regression models, the quantitative values of qPCR and ELISA were used for analysis, qPCR values on an ordinal scale and the ELISA results as continuous values (Table 2). The $\mathrm{S} / \mathrm{P}$ values in August 2008 were found to be associated with the qPCR values from the same day $(P<0.001)$. The $\mathrm{S} / \mathrm{P}$ values in January to February 2009 were found to be significantly associated both with the qPCR results from August 2008 and January to February 2009, as well as the S/P values from August $2008(P \leq 0.001)$. Finally, the $\mathrm{S} / \mathrm{P}$ values in April to June 2009 were significantly associated with the qPCR values from January to February and April to June $2009(P<0.003)$, as well as the $\mathrm{S} / \mathrm{P}$ values from August 2008 and January to February $2009(P<$ 0.003), but not with the qPCR values found in August $2008(P=0.34)$.

The relationship between PCR results and days in lactation after calving, parity, SCC, milk yield, fat percentage, and protein percentage was analyzed at the cow level while accounting for repeated measures up to 3 sampling dates and accounting for a random effect of the herd (Table 3). The multivariable analyses identified a significant increasing shedding level of $C$. burnetii DNA (decreasing qPCR value) with increasing parity $(P<0.05)$ and increasing protein percentage $(P$ $<0.0001)$.

\section{Analysis of BTM}

The concentration of $C$. burnetii in BTM showed marked variation between sampling times and herds (Figure 3). Coxiella burnetii DNA could be detected from $74(49 \%)$ of the BTM samples and the average quantity of $C$. burnetii among positive samples was 75 cells $/ \mathrm{mL}(\mathrm{SD}=103)$ and the highest concentration found was 500 cells $/ \mathrm{mL}$. The average concentration per herd among positive samples during the project period varied between 1 and 98 cells $/ \mathrm{mL}$.

An overall correlation between the $\mathrm{S} / \mathrm{P} \%$ and $C$. burnetii concentration in BTM was found $(\mathrm{R}=+0.33, P<$ 0.001). Figure 4 shows a scatter plot of the values. On a herd basis, however, this relationship was significant in only 3 herds (No. 78, 88, and 109), whereas in the remaining 9 herds, this was not the case.

The relationship between cow samples and BTM samples were analyzed for the 3 sampling events where these samples were obtained simultaneously. The quantitative results from the BTM samples were compared with the prevalence levels of $C$. burnetii DNA and antibodies in cow milk samples (Table 4). This showed a statistically significant correlation between the S/P values in BTM and all the 3 other variables. No correlation was found between percent PCR-positive cow samples and the C. burnetii concentration in BTM. A correlation was, however, found between the $\mathrm{Cq}$ values of the cow samples (weighted according to milk yield) and the $C$. burnetii concentration in BTM $(P=0.02$, Spearman correlation coefficient). 
Table 2. Regression analysis of the association between sample/positive control (S/P) values and quantitative PCR (qPCR) values in cow milk sampled in August 2008, January to February 2009, and in April to June $2009^{1}$

\begin{tabular}{|c|c|c|c|c|c|c|}
\hline \multirow[b]{2}{*}{ Dependent variable } & \multicolumn{2}{|c|}{ August 2008} & \multicolumn{2}{|c|}{ January-February 2009} & \multicolumn{2}{|c|}{ April-June 2009} \\
\hline & $\mathrm{S} / \mathrm{P}$ & qPCR & $\mathrm{S} / \mathrm{P}$ & qPCR & $\mathrm{S} / \mathrm{P}$ & qPCR \\
\hline S/P Aug 2008 & - & $* * *$ & - & - & - & - \\
\hline S/P Jan-Feb 2009 & $* * *$ & $* * *$ & - & $* * *$ & - & - \\
\hline S/P Apr-Jun 2009 & $* *$ & NS & $* *$ & $* * *$ & - & $* * *$ \\
\hline
\end{tabular}

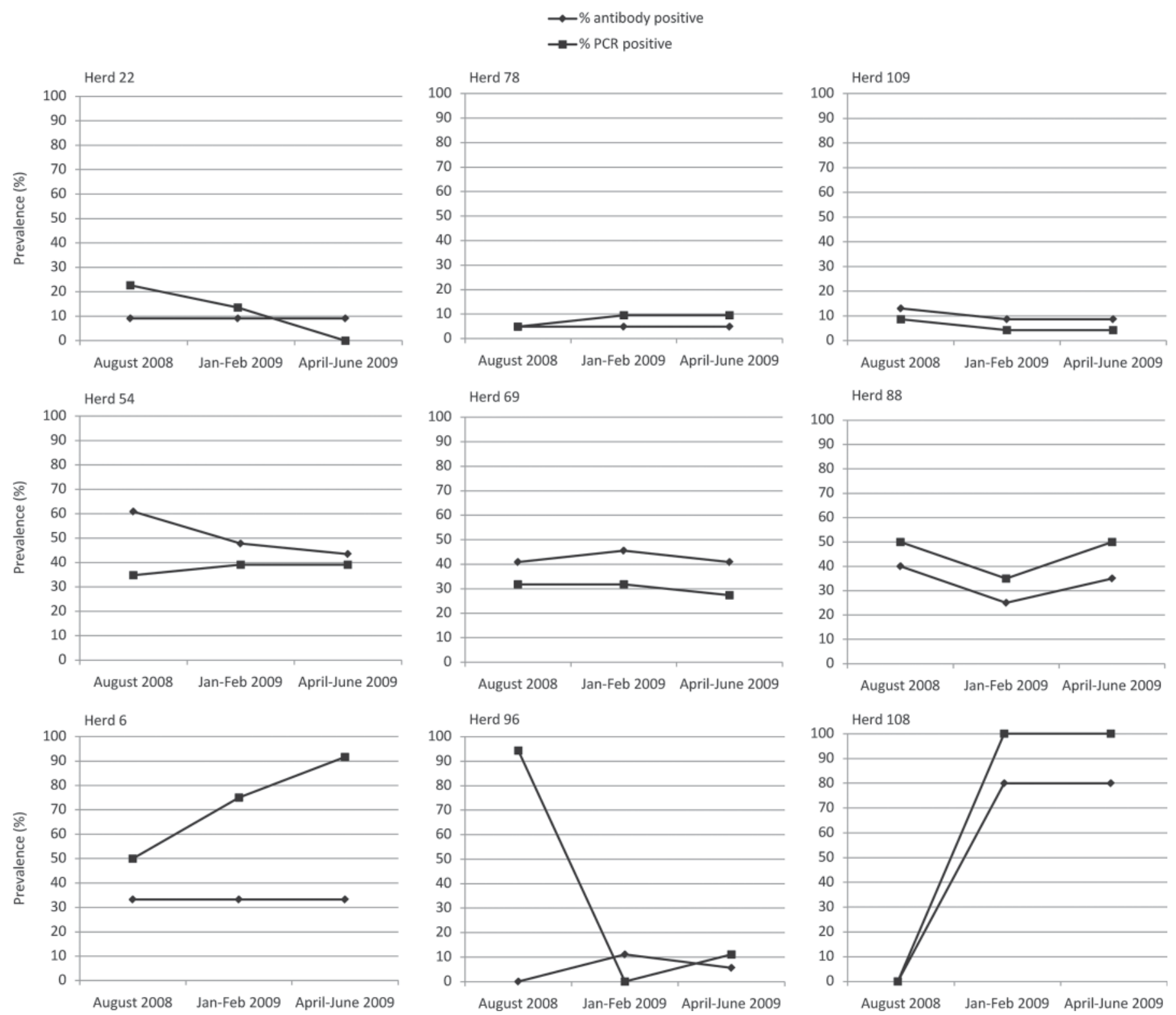

Figure 2. Herd profiles for prevalence (\%) of Coxiella burnetii DNA and antibodies among 166 cows in 9 Danish dairy herds sampled 3 times during an 11-mo study period. Upper row: herds with steady low levels; middle row: herds with stable medium levels; bottom row: herds with change in DNA or antibody levels. 
Table 3. Statistical analyses of relationship between PCR result of individual cow milk samples and intrinsic cow production traits ${ }^{1}$

\begin{tabular}{|c|c|c|c|c|c|c|c|c|}
\hline Analysis & $\begin{array}{l}\text { Dependent } \\
\text { variable }\end{array}$ & Time & DIM & Parity & $\mathrm{SCC}$ & $\begin{array}{l}\text { Milk } \\
(\mathrm{kg})\end{array}$ & $\begin{array}{l}\text { Fat } \\
(\%)\end{array}$ & $\begin{array}{c}\text { Protein } \\
(\%)\end{array}$ \\
\hline Bivariable & PCR ordinal & 1 & 0.18 & 0.03 & 0.87 & 0.46 & 0.59 & 0.86 \\
\hline Bivariable & PCR ordinal & 2 & 0.23 & 0.22 & 0.17 & 0.09 & 0.15 & 0.47 \\
\hline Bivariable & PCR continuous & 1 & 0.05 & 0.007 & 0.86 & 0.32 & 0.38 & 0.98 \\
\hline Bivariable & PCR continuous & 2 & 0.23 & 0.22 & 0.24 & 0.11 & 0.27 & 0.57 \\
\hline Bivariable & PCR continuous & 3 & 0.85 & 0.57 & 0.77 & 0.50 & 0.93 & 0.82 \\
\hline \multicolumn{9}{|c|}{ Repeated measures analysis } \\
\hline Multivariable & PCR ordinal & & & 0.04 & & & & $<0.0001$ \\
\hline Multivariable & PCR continuous & & & 0.05 & & & & $<0.0001$ \\
\hline
\end{tabular}

${ }^{1}$ For the multivariable analyses, only models with values below 0.05 are included. Significant results are indicated in bold.

\section{DISCUSSION}

Agger et al. (2010) found antibodies against $C$. burnetii in $59 \%$ of BTM samples from 100 randomly selected Danish dairy herds. In the present investigation including 12 herds, $25 \%$ of the 1,514 individual cow samples were seropositive, whereas $32 \%$ were positive for C. burnetii DNA. Some of these animals probably excreted viable $C$. burnetii organisms, as viable bacteria in milk samples found positive for $C$. burnetii by PCR have been reported previously (Barlow et al., 2008; Loftis et al., 2010). Deoxyribonucleic acid shedding in individual milk samples was also investigated by Guatteo et al. (2007b) who reported a mean within-herd prevalence of milk-shedder cows of $18.5 \%$ (range 0-45\%) in 14 French dairy herds. In another study including 5 French dairy herds, Guatteo et al. (2007a) reported that approximately $40 \%$ of the cows were shedders. Shedding of $C$. burnetii through milk has, on the other hand, been regarded to have a minor
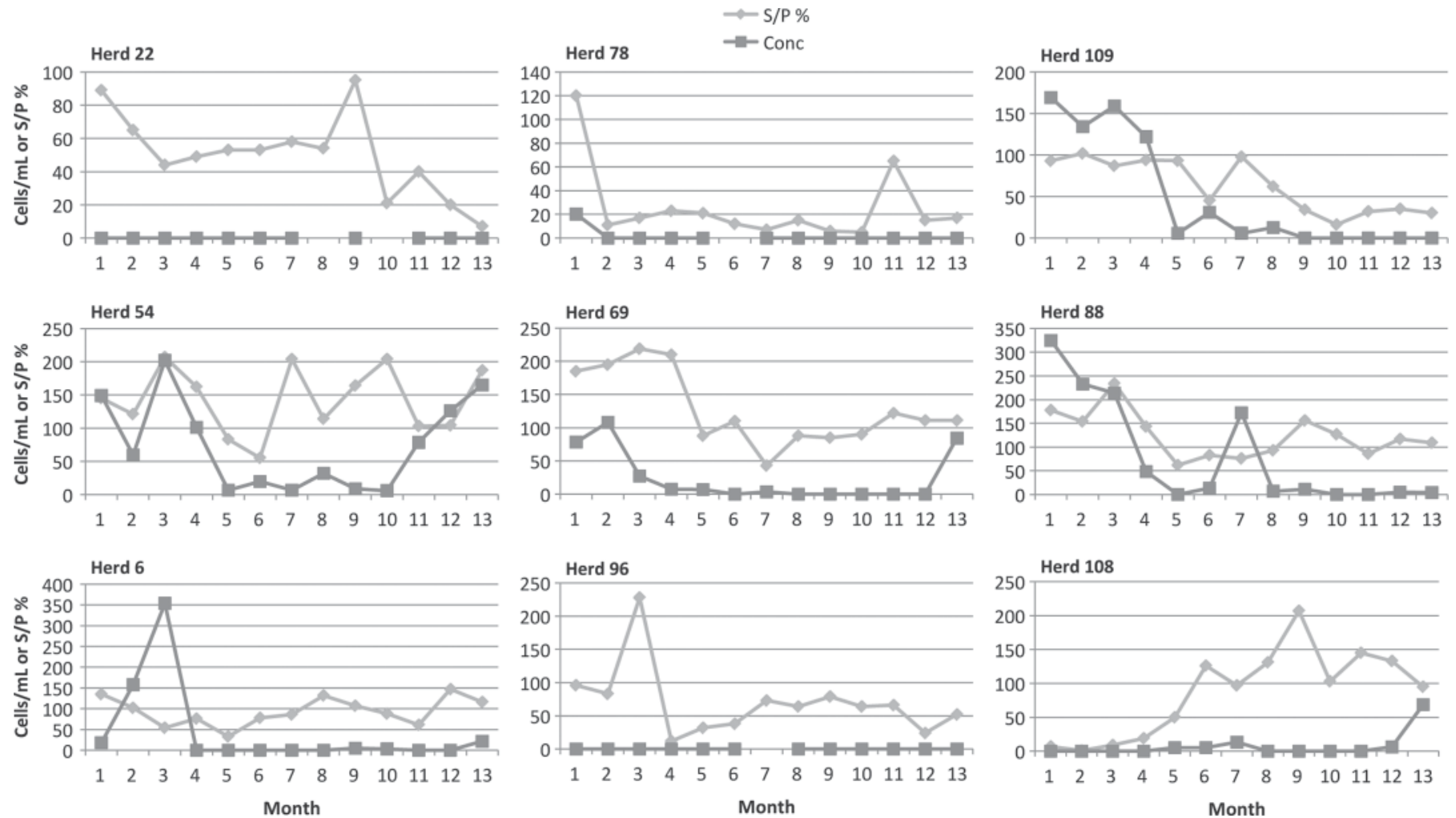

Figure 3. Longitudinal profiles of Coxiella burnetii concentrations and antibody levels in bulk tank milk samples from 9 Danish dairy herds (the same as in Figure 2). The y-axis shows the C. burnetii concentration (Conc) as cells/mL and antibody levels as sample/positive control $(\mathrm{S} / \mathrm{P}) \%$. 
Table 4. Correlation between percent of cows positive by PCR and serology in the herd and concentration of Coxiella burnetii cells and antibodies in bulk tank milk (BTM) ${ }^{1}$

\begin{tabular}{llcc}
\hline Item & $\begin{array}{c}\text { BTM S/P } \\
\text { Value }^{2}\end{array}$ & $\begin{array}{c}\text { Cow \% PCR } \\
\text { positive }\end{array}$ & $\begin{array}{c}\text { Cow \% serology } \\
\text { positive }\end{array}$ \\
\hline Cow \% PCR positive & $0.68(<0.0001)$ & & \\
Cow \% serology positive & $0.59(<0.001)$ & $0.61(<0.0001)$ & $0.32(0.06)$ \\
BMT C. burnetii cells $/ \mathrm{mL}$ & $0.33(0.02)$ & $-0.02(0.92)$ & \\
\hline
\end{tabular}

${ }^{1}$ Pearson correlation coefficient $(P$-value) in parentheses.

${ }^{2} \mathrm{~S} / \mathrm{P}$ value $=$ sample/positive control value.

role in transmission of Q-fever to humans (Maurin and Raoult, 1999; Rodolakis, 2009).

We decided to extract DNA from the cream layer of the cow milk samples. This was based on a pilot study showing that more samples were positive from the cream layer than from a cell pellet after centrifugation, and also on the data reported by Rodolakis et al. (2007). Their study indicated that DNA extraction from the cream performed as well as extraction from full milk and, in some cases, could make the test even more sensitive. However, when testing 55 parallel samples from one of the herds with high Coxiella-prevalence in this study, we found no significant difference in the number of positive samples and $\mathrm{Cq}$ levels between the $2 \mathrm{DNA}$ extraction methods. As the sample volume and the amount of cream obtained from the different samples showed some variation, we only report the results obtained semiquantitatively in terms of the $\mathrm{Cq}$ values.

Most investigations reporting quantitative values of $C$. burnetii use a calibration standard based on the Nine Mile strain. The analyses will be affected if the number of IS elements differs between the Nine Mile strain and $C$. burnetii isolates in the samples and the absolute values should, therefore, be interpreted with some caution. Assuming that the extraction from similar volumes of the cream layer and full milk generally gives a similar Coxiella DNA yield, the milk samples in the present study having Cq values below 28 (31\% of the samples) should have had Coxiella concentrations above $10^{2}$ cells $/ \mathrm{mL}$, when assuming that Danish C. burnetii strains have the same number of IS1111 elements as the Nine Mile strain. This corresponds well

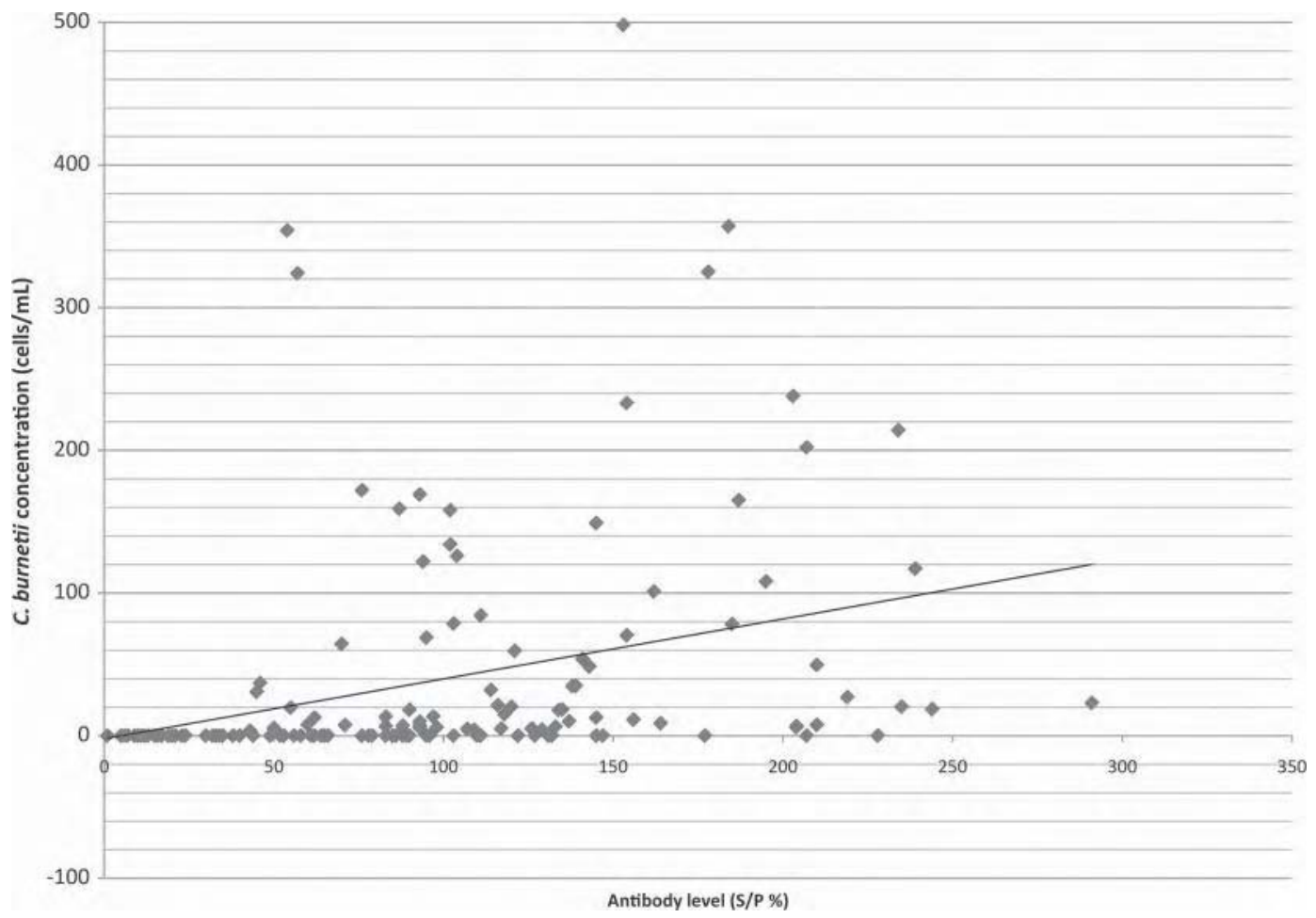

Figure 4. Scatterplot and linear regression line of Coxiella burnetii (C. burnetii) concentrations and antibody levels in bulk tank milk samples from 12 Danish dairy herds. $\mathrm{S} / \mathrm{P}=$ sample/positive control. 
with the quantitative results obtained from analyzing the BTM samples where an average of $10^{2}$ cells/ $\mathrm{mL}$ was found among the positive samples (50\% of all samples). Only $2 \%$ of the positive cow milk samples had $\mathrm{Cq}$ values in the range 16 to 22 , corresponding to concentrations above $10^{4}$ cells $/ \mathrm{mL}$. Only a few studies have dealt with concentration of Coxiella in bovine milk samples. Guatteo et al. (2007a) investigated 5 cattle herds for shedding in milk at different stages of lactation and reported median concentrations between 5 and $10^{3}$ cells $/ \mathrm{mL}$ and maximal values ranging from 25 to $10^{5}$ cells $/ \mathrm{mL}$, depending on the kinetic shedding pattern of the animal. Guatteo et al. (2007b) also reported an average Coxiella titer of $10^{2.3}$ in BTM in 31 positive herds (range: $10^{0.3}$ to $10^{3.7}$ ), whereas Kim et al. (2005) reported that PCR positive cows shed between 10 and $10^{4}$ C. burnetii cells $/ \mathrm{mL}$.

How cattle become infected with $C$. burnetii is not documented. Likely options are aerosols, ingestion of infected materials, intrauterine infections, or ascending teat infections. The presence of milk antibodies might reflect a systemic response or a local antibody production (Rodolakis, 2009). It can be expected that antibody production start weeks after onset of an infection, but as both DNA shedding and antibody secretion can be transient or intermittent (Guatteo et al., 2007a), a clear relationship between these 2 parameters cannot be expected. Barlow et al. (2008) found a strong association between $C$. burnetii levels in milk measured by $\mathrm{qPCR}$ and chronic subclinical mastitis, indicating the possibility of mammary gland-specific manifestations of $C$. burnetii infections in cattle giving rise to local production of antibodies.

To investigate the relationship between antibody levels and bacterial shedding, a data set including only data from the 166 cows, which had been sampled at all 3 sampling points, was used. A plot of the prevalence of positive serology and PCR results showed different patterns among the herds (Figure 2). For most of the herds, a stable seroprevalence and proportion of DNA shedders at a low or intermediate level was found. In 2 herds (No. 6 and 108) a marked increase in DNA shedders was observed; in herd 108, this increase was followed by an increase in seroprevalence. In herd 108, the most plausible explanation is an introduction of the infection to the herd between August 2008 and January 2009. In herd 96, a marked decrease in DNA shedders were seen from the first to the second visit, possibly reflecting a decreasing infection level. This is supported by the fact that only low DNA levels (Cq values above 33) were found in this herd at the first visit.

The dynamics between the presence of antibodies and DNA shedding (Cq values) in cow milk were analyzed quantitatively using a multivariable regression model.
A significant association was found between the $\mathrm{S} / \mathrm{P}$ titer and the DNA shedding level at the same and the preceding visit. In the same model, a significant association also occurred between the current $\mathrm{S} / \mathrm{P}$ level and the S/P level 3 to 7 mo earlier.

The multivariable regression model investigating the relationship between qPCR and intrinsic cow factors identified a significant association between DNA shedding level and parity and protein percentage. A similar association has not been reported earlier and deserves further attention. No association between qPCR results and increasing DIM was found, which corresponds to what was reported by Rodolakis et al. (2007). However, an association between $C$. burnetii shedding and increasing DIM was reported by Barlow et al. (2008). In contrast to their study, no association between SCC and $C$. burnetii shedding was found in the present investigation, indicating that in the Danish herds, the presence of $C$. burnetii in milk was not linked to mammary gland inflammation.

Further information on the herd infection dynamics can be obtained from the longitudinal investigation of BTM samples (Figure 3). For most of the herds, the curves showing percent antibody-positive cows (Figure 2) and S/P percent in BTM (Figure 3) had generally the same shape. The statistical analysis also showed that these values were highly correlated (Table 4). However, for most of the herds, a very low correspondence was found between the curves showing percent PCR-positive cows and the $C$. burnetii concentration in BTM. No correlation between these values was found in the statistical analysis (Table 4). On average, 46 cow samples were randomly taken from each herd and, consequently, they were most likely representing the $C$. burnetii content of the BTM. However, theoretically, a random sample may not represent the population it is sampled from. A large number of animals might be PCR positive at a low level and the dilution effect from other noninfected cows could nevertheless make the PCR on BTM negative (as earlier mentioned for herd 96). In herd 108, all cows that were DNA tested 3 times were PCR positive at the second and third sampling (Figure 2 ). However, only $85 \%$ of all cows tested in the herd were positive for $C$. burnetii DNA (Table 1 ) and the average $\mathrm{Cq}$ value of these cow samples were as high as 31, probably explaining much of the deviance between the curves. It could, therefore, be expected that a higher correspondence could be found between the C. burnetii DNA content of BTM and the cow samples if both were treated as quantitative variables. The $\mathrm{Cq}$ values of the cow samples were transformed by weighting them according to the milk yield of the cows. A significant correlation was found between the weighted $\mathrm{Cq}$ values of the cow samples and the $C$. burnetii concentration in 
BTM, even though the cow samples only represented a subset of the herd.

\section{CONCLUSIONS}

A qPCR method with an internal control was evaluated for detection of $C$. burnetii in milk. No increased sensitivity was found when the cream fraction was analyzed compared with the full milk. The results show that the prevalence levels of $C$. burnetii organisms and antibodies in dairy cattle in most of the herds were rather stable during a period of 11 mo. Only in 3 herds was a change in the infection level observed. Apparently, the herds had bacterial reservoirs that were capable of transmitting and maintaining the infection in the herd. A significant association was found between the presence of $C$. burnetii DNA and antibodies in cow milk and BTM. The levels of both DNA and antibodies in cow milk were indicative for the levels measured 4 to 7 mo later. The levels of $C$. burnetii DNA in milk were significantly associated to parity and protein percent at the cow level but not to DIM, SCC, daily milk yield, and fat percent. The transmission dynamics of $C$. burnetii in cattle herds and the relationship to animal health deserves continuous attention and research.

\section{ACKNOWLEDGMENTS}

The DNA from the C. burnetii Nine Mile strain RSA 493 was kindly provided by S. Villumsen (Statens Serum Institut, Copenhagen, Denmark). Deoxyribonucleic acid from defined amounts of $C$. burnetii was provided by E. Rousset [Agence nationale de sécurité sanitaire de l'alimentation, de l'environnement et du travail (ANSES), Maisons-Alfort, France]. The authors thank Mahshad Rezaali, Mari Salah, Birgitte Møller, and Tamara Plambeck for skillful technical assistance (all from National Veterinary Institute, Technical University of Denmark, Copenhagen V, Denmark).

\section{REFERENCES}

Agger, J. F., A.-B. Christoffersen, E. Rattenborg, J. Nielsen, and J. S. Agerholm. 2010. Prevalence of Coxiella burnetii antibodies in Danish dairy herds. Acta Vet. Scand. 52:5.

Barlow, J., B. Rauch, F. Welcome, S. G. Kim, E. Dubovi, and Y Schukken. 2008. Association between Coxiella burnetii shedding in milk and subclinical mastitis in dairy cattle. Vet. Res. 39:23.

Bødker, R., and A.-B. Christoffersen. 2008. Occurrence of the bacterial zoonosis Q fever in Danish cattle herds. Dan. Veterinaertidsskr. 91:16-22. (in Danish).

Guatteo, R., F. Beaudeau, A. Joly, and H. Seegers. 2007a. Coxiella burnetii shedding by dairy cows. Vet. Res. 38:849-860.

Guatteo, R., F. Beaudeau, A. Joly, and H. Seegers. 2007b. Assessing the within-herd prevalence of Coxiella burnetii milk-shedder cows using a real-time PCR applied to bulk tank milk. Zoonoses Public Health 54:191-194.

Guatteo, R., H. Seegers, A.-F. Taurel, A. Joly, and F. Beaudeau. 2011. Prevalence of Coxiella burnetii infection in domestic ruminants: A critical review. Vet. Microbiol. 149:1-16. doi:10.1016/j.vetmic.2010.10.007.

Hansen, M. S., A. Rodolakis, D. Cochonneau, J. F. Agger, A.-B. Christoffersen, T. K. Jensen, and J. S. Agerholm. 2011. Coxiella burnetii associated placental lesions and infection level in parturient cows. Vet. J. doi:10.1016/j.tvjl.2010.12.021.

Kim, S. G., E. H. Kim, C. J. Lafferty, and E. Dubovi. 2005. Coxiella burnetii in bulk tank milk samples, United States. Emerg. Infect. Dis. 11:619-621.

Loftis, A. D., R. A. Priestley, and R. F. Massung. 2010. Detection of Coxiella burnetii in commercially available raw milk from the United States. Foodborne Path. Dis. 7:1453-1456. doi:10.1089/ fpd.2010.0579.

Maurin, M., and D. Raoult. 1999. Q fever. Clin. Microbiol. Rev. $12: 518-553$

Panning, M., J. Kilwinski, S. Greiner-Fischer, M. Peters, S. Kramme, D. Frangoulidis, H. Meyer, K. Henning, and C. Drosten. 2008. High throughput detection of Coxiella burnetii by real-time PCR with internal control system and automated DNA preparation. BMC Microbiol. 8:77.

Rodolakis, A. 2009. Q fever in dairy animals. Ann. N. Y. Acad. Sci. 1166:90-93.

Rodolakis, A., M. Berri, C. Héchard, C. Caudron, A. Souriau, C. C. Bodier, B. Blanchard, P. Carmuset, P. Devillechaise, J. C. Natorp, J. P. Vadet, and N. Arricau-Bouvery. 2007. Comparison of Coxiella burnetii shedding in milk of dairy bovine, caprine, and ovine herds. J. Dairy Sci. 90:5352-5360. 